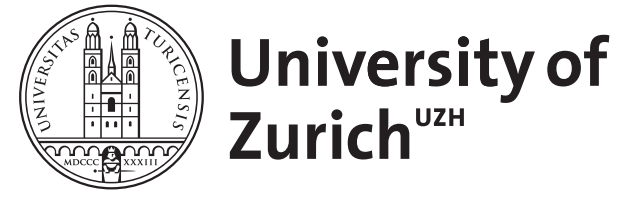

Zurich Open Repository and Archive

University of Zurich

University Library

Strickhofstrasse 39

CH-8057 Zurich

www.zora.uzh.ch

Year: 2012

\title{
Managing creativity in media companies
}

von Rimscha, M Bjørn ; Przybylski, Pamela

Posted at the Zurich Open Repository and Archive, University of Zurich

ZORA URL: https://doi.org/10.5167/uzh-65225

Book Section

Published Version

Originally published at:

von Rimscha, M Bjørn; Przybylski, Pamela (2012). Managing creativity in media companies. In: Kolo, Castulus; Döbler, Thomas; Rademacher, Lars. Wertschöpfung durch Medien im Wandel. Baden-Baden: Nomos, 85-102. 


\title{
Managing creativity in media companies
}

\author{
M. Bjorn von Rimscha / Pamela Praybylski
}

\section{Introduction}

Thomas Gottschalk has been one of the most popular show hosts in German TV for over 25 years. When his show "Gottschalk live" was taken off the schedule the management of creativity seemed to have failed. Breaking with the routine of "Wetten dass...?" Gottschalk was trying out something different and he failed to meet even the moderate audience numbers planned for. Except for the host all elements of the show have been altered during the season seemingly making the viewers eyewitnesses of creativity in progress. The broadcaster praised Gottschalk for bringing his individual creativity to the show. However, the audience turned away, the broadcaster aborted the experiment while observers criticized the concept and changes as inadequate and shortsighted. Was this creativity or the management of creativity that had failed? The case illustrates the range of questions that emerge when trying to locate, describe and explain creativity and its role within media companies. What is creativity? Can it be managed at all? And: Does it "pay off"? Creativity is a term essential to media production processes posing specific demands towards management in media companies.

The preoccupation with the circumstances of media production has increased in the context of the politically initiated discussion on the cultural and creative industries. The importance of these industries is accounted for with the digitization, its influence on society, and the changing demands on economy associated with it. The terms creativity and culture are used as keywords for a new economy and the ability to cope with the challenges of the digitized and the information society. Still definitions of both terms aren't precise (or not even defined at all, e.g. see KEA European Affairs 2009) nor are they being used consistently. Disunity moreover characterizes the concepts of the creative and cultural industries, being called creative, cultural, experience, content or copyright industries as well as creative or cultural economy and resulting in a different range of companies and industries being integrated into the concept (see e.g. the list by KEA European Affairs et al. 2006: 45-55). Although the concepts differ they all include the media calling them part of these industries and connecting them to the term creativity: The element unifying the cultural and creative sectors is the creative act (Söndermann et al. 2009: xi). The Creative Industries Task Force (CITF) 
of the British Department of Culture, Media and Sport therefore defines the creative industries as "those industries which have their origin in individual creativity, skill and talent" (Creative Industries Task Force (CITF) 2001: 5). This perspective on the creative industries with creativity at the center (also see Banks et al. 2002: 256f.) is being applied in international contexts. The research conducted within the frames of these political initiatives is able to amplify the body of research on media production with knowledge on the organizations and individuals working in this area. Moreover it describes or at least mentions a relationship between organizations of media production and creativity, while it frequently misses to specify the terms used and tends to misuse them. Especially the term creativity has been "abused and over-used" (Hesmondhalgh / Baker 2011: 2) primarily by policy-makers becoming a doctrine in political discussions (Schlesinger 2007: 377). Apart from that, it had been focused on by management analysts and economists using a psychological perspective connecting it to motivation and innovation (Hesmondhalgh / Baker 2011: 3). Karow highlights the recent detection of the potential value of creativity in business process management especially in businesses based on innovation and/or intellectual property (Karow 2011: 2f.). Despite of the wide usage and thus blurring of the term "creativity" its role in media sticks out as it will be argued in the course of this paper.

In the following we will provide a literature review on creativity especially in the media industry and discuss its contribution to value creation. The article is structured as follows: First we will provide different approaches to define creativity and creative workers (1). Secondly we will have a look at the literature on creativity as an organizational trait and present common suggestions on how to manage creative workers to create creative organizations (2). We will then step back and ask the question to what extent general findings are applicable to the media industry (3), before we finally discuss the contribution of creativity to value creation in media firms (4).

\section{Creativity and creative workers}

"We are creative animals, homo creator" (Howkins 2002: xiv). The wide definitions used by some authors conceptualizing economic branches and companies as part of the creative industries and the frequent use of the term in everyday life - attributing persons, businesses, products etc. as creative (see e.g. Bilton 2007: xiii) - implies the question on the actual meaning of creativity and creative. Everyone has an individual idea of 
what these terms might mean (Klausen 2010: 348). Authors agree on the complexity of the term and the difficulties in defining it. Since creativity itself seems hard to grasp many definitions "use characteristics of the creative product as the distinguishing signs of creativity" (Amabile 1983: 358 ) or focus on the process "which results in a novel work or output" (Greenberg 1992: 76). These approaches require creative workers to be productive, since - following their argumentation - we can only tell that creativity was at work if a (useful) product has emerged. From everyday experience we all know that it takes some contemplative detours and the detection of (creative) blind alleys before an idea is fully formed. While having "a propensity for resulting in a novel work" (Klausen 2010: 349) a creative process might but does not have to have a concrete result. A first hint that judging the value of creativity might be difficult. Getting to the black-box like core of creativity thus calls for a closer look on the process that leads - or sometimes does not lead - to a creative output. Unfortunately definitions that take this route regularly trade one ambiguous term for another such as incubation and illumination (Wallas 1926) or imagination (Scott 1995: 66). According to Henry creativity "is a thinking process associated with imagination, insight, invention, innovation, ingenuity, intuition, inspiration and illumination" (Henry 1991: 3). By accumulating vague terms rather than clear starting points for analysis and by naming some characteristics that point to the deprecated (see e.g. Sawyer 2006: 15-18; Kerrigan / McIntyre 2010: 115f.) romanticist idea of creativity originating in individual genius such a list obviously leads us nowhere. Thus, we should try to approach the issue from a different angle which is the objective of creativity.

Generally the literature distinguishes between three different types of creativity: economic (entrepreneurship), technological (invention), and cultural (art and entertainment). The respective object of creativity calls for different processes of creative thinking and for different talents and skills of the creative worker. Entrepreneurship is very much about seizing opportunities and monetizing ideas. While artists and creative talents value creativity for its own sake from an economic perspective novelty is not enough. "For an idea to be truly creative it must also be appropriate and useful" (Henry 1991: 3). In the following we will not go into details of creativity in terms of entrepreneurship, but refer to the article by Gossel and Will in this volume. Technological and cultural creativity can be distinguished by their starting point. While some inventions happen by accident, most of the time technological creativity is triggered by an en- 
gineering problem that can be more or less clearly defined. Cultural creativity does not necessarily need a problem to be solved to begin with.

This background leads to two fundamentally different approaches towards creativity. One school of thought proclaims that everybody can be as creative as anybody else. Creativity would be similar to playing an instrument, carrying out a sport or writing a text without typos. All it takes is some discipline and of course a lot of training. Consequently this perspective is heralded by a whole industry providing training in creative problem solving (CPS). Proponents suggest to use "Applied Imagination" (Osborn 1963), "Lateral thinking" (de Bono 1981), "Synectics" (Gordon 1961) or "Mind mapping" (Buzan 1977) to remain a "Rationale manager" (Kepner / Tregoe 1965) and conceptualize "Creativity as an exact science" (Althuller 1984).

The other school of thought argues that the CPS approach is actually not about (cultural) creativity but just about (technical) problem solving. While it might be useful in the context of an engineering problem in the development of new headlights for a car, it is less helpful in the context of creative industries. A problem like "We need a great new game show for the Monday night slot" might be addressed by everybody trained in CPS; however, it is unlikely that the outcome will be a new format hit. From this perspective there remains a certain notion of myth and subconsciousness about creativity. Research concentrating on this notion states that not all men are creatively equal, but creative people are somewhat "special". Creativity is even located in a different part of the brain (Mintzberg 1976). Creative people would be different from others in their use of the right side of the brain and their brains would be less effectual in suppressing associations and imaginations that might or might not be irrelevant. Creativity is associated with mental disorders since it would equally rely on primary process thought rather than secondary process thought - roughly speaking on feeling rather than logic. While schizophrenics would be able to think in terms of primary process only and psychotics would have trouble to control where they are on the primary-secondary continuum, creative minds could delve into dreamlike thinking on the primary level in order to surface useful ideas to be implemented on the secondary level (Torr 2008: 55-57). The occasional lack of level control is thus used to explain why creatives are at times so incredibly hard to work with. Still these findings are contested: Sawyer states that creativity is a "whole-brain function" (Sawyer 2006: 95). He concludes his review of the relevant literature that biology is not able to explain creativity. 
At the core of the second perspective on creativity is the four step process of creativity described by Wallas (1926): Preparation, incubation, illumination and verification. Similarly Csikszentmihalyi describes five stages of the creative process: preparation, incubation, insight, evaluation and elaboration (Csikszentmihalyi 1996: 83-86). While preparation can be put into a business process, incubation excludes itself from too much standardization as it is thought to tackle the problem "below the threshold of consciousness" (Kerrigan / McIntyre 2010: 122). Putting a problem aside to let the subconscious work on it, is exactly that kind of mystical black box managers have problems to cope with. How can you tell a creative is incubating or lazy? How long a time span is necessary for incubation to - as Wallas calls it - illumination? Do you just have to trust your creative worker or are there means to get to the Eureka!-moment faster? Csikszentmihalyi moreover points out that the steps might "overlap and recur several times before the process is completed" (Csikszentmihalyi 1996: 83). The steps of "verification" or "evaluation and elaboration" finally link the idea to the (business) reality. Does the idea work within the constraints of the setting? Is it only fancy and new or also "appropriate, useful, correct or valuable" (Amabile 1996, see also Sternberg / Lubart 1999) and meaningful (Howkins 2002: ix)? Some authors highlight the breaking of rules as being part of a creative process (Bilton 2007: xiv). But, as it needs to remain appropriate, it still has to meet certain constraints thus it "is both about breaking with norms and complying with norms. This doesn't have to be a paradox, as long as one is talking about different sets of norms - breaking with the narrow or local ones while still meeting some general requirements" (Klausen 2010: 355). This idea implies that creativity depends on the structures and rules of a specific context as in Csikszentmihalyi's systems model of creativity. The model consists of three elements: The individual influenced by its personal background, the specific domain as part of the culture and the field being the social organization of the domain (Csikszentmihalyi 1999, see also Hooker et al. 2003; Kerrigan 2010; Kerrigan / McIntyre 2010). Due to the model creativity takes place when an individual (e.g. documentary film maker) changes a domain (e.g documentary) by bringing in something new that is being accepted and selected by the field, i.e. the people and organizations within the field. Kerrigan and McIntyre take the narrative structure of reality TV that had been introduced and first applied by Paul Watson (his contribution to the documentary field is described by Baker 2006) as an example (Kerrigan / McIntyre 2010: 120). Authors describe this type of creativity as "large C" to distinguish it from creativity in everyday life (e.g. changing the recipe when an ingredient is missing) 
which is being called "small c" (Csikszentmihalyi 1999; Sawyer 2006: 27). Consequently in accordance to the systems model creativity means changing the culture. Domain specific knowledge and experience is a precondition to be "creative" in this sense. Creativity moreover does not exist without an evaluative context.

Csikszentmihalyi conceptualizes his model as applicable to nearly all domains of culture (while pointing out that it is easier to detect and therefore achieve creativity in closely structured domains). This model does not exclusively apply to specific industries associated with creative products and creative persons, while current discussions do when using creativity as a precondition to define cultural and creative industries (see above). Based on the idea of creativity as a starting point of definition creative workers are being defined as people whose work is primarily associated with creativity. Describing creativity as "the manipulation of symbols for the purposes of entertainment, information and perhaps even enlightenment" Hesmondhalgh introduces the term "symbolic creators" (Hesmondhalgh 2007: 5) to describe creative workers whose work is "centred on the activities of symbol-making" (Hesmondhalgh / Baker 2011: 9). This description of creative workers indicates that they are people capable of cultural creativity; their activities reaching beyond technical problem solving. It again points to a context dependence of creativity in the sense of dependence (of individual creativity) on the social and cultural context. Although frequently described in reference to the individual, creativity may also be attributed to groups (see e.g. Paulus / Nijstad 2003) making interactions of people a place for creativity and source of creative output. This line of thought leads to considerations of organizational creativity.

\section{Organizational creativity or how to manage creativity}

From a managerial point of view individual creativity is nice to have but for creativity to be valuable you might want to have an innovative organization, one that can turn symbol-making into productive innovations. This is all the more important since most creative industries rely on teamwork. While a painting can be created by one gifted creative (albeit imbedded in a social context; see e.g. Lubart / Mouchiroud 2003: 128), media products such as TV-shows or movies are co-created by combining the work of numerous talents (Caves 2000: 5f.). Thus "creativity requires context and organization" (Jeffcutt / Pratt 2002: 226). 
An ever growing body of literature has tried to analyze the relationship between individual creativity and organizational innovation, defining the latter as the aspect of creativity that can be monetized (Woodman et al. 1993; Amabile 1997; Ekvall 1997). Andriopoulos (2001) provides a useful literature review and distills five factors affecting organizational creativity: (1) organizational climate, (2) leadership style, (3) organizational culture, (4) resources and skills, and (5) structure and systems. He believes these insights to be useful for practitioners, but at the same time criticizes that most of the recommendations stem from purely conceptual papers or surveys. There would be a lack of multilevel studies that really allow analyzing the interplay between individual and organization in terms of creativity.

The very same lamentation is put forward in the context of media management. Research on innovation management in media companies links innovation to creativity (Mierzejewska / Hollifield 2006: 48-52; Küng 2008: 145; Fröhlich 2010: 29). Creativity stands for the generation of an idea whereas innovation implies the economic exploitation of that idea. Therefore, creativity is a necessary but not a sufficient condition for innovation (Fröhlich 2010: 29-30). According to this argumentation the creative process is the starting point for an analysis of media production, nevertheless „few studies in the media management literature have examined the actual management of the creative process" (Mierzejewska / Hollifield 2006: 52). Recent studies have focused on this process from an information systems perspective aiming at the development of an IT infrastructure for creative fields of work. The authors (see Seidel 2009; Seidel et al. 2009; Becker et al. 2008, 2011; Karow 2011) point out that creative work is constituted as a combination of creative, i.e. uncertain aspects and non-creative, i.e. controllable aspects. Therefore they suggest to refer to creativity-intensive processes (CIP) where creative tasks are located within a structured workflow and the work of creatives is combined with other functions (Seidel 2009; Becker et al. 2011). Variability is described as an inherent part of a creativity-intensive process. The authors try to minimize the ambiguous aspects of creativity by identifying those elements that can be tackled with standard management techniques. Uncertainty is reduced as much as possible, however without completely eliminating it to leave room for creativity: "Pockets of creativity" still exclude themselves from strictly rational planning.

In an industry perspective creative and "humble" functions are distributed between different companies in a production network (Altmeppen et al. 2007). The attribution of competences determines the role of a 
player. Interestingly these attributions are not consistent but dependent on the market structure and the tradition of collaboration between producers and commissioners. Consequently the producers - although usually coordinating, recruiting and employing the creative personnel and developing the creative content - are frequently but not always described as playing the creative part. Fröhlich found that broadcasters who conceive themselves as creative do not expect the producer to be creative and do not have trust in the producer's creative skills. In consequence the producers themselves show a lack of self-confidence concerning their creativity (Fröhlich 2010: 267-269). Managing creativity and creative workers thus calls for an examination of the workers' self-concept, their awareness of their own competences, and the attribution of those competences by their context as a first step.

But what does the literature actually suggest about how to deal with creative workers when aiming at increasing the innovative output?

Redmond, Mumford, and Teach analyzed the effect of leader behavior on subordinate creativity. They conclude that "acknowledging the value of dissent and encouraging diversity of opinion may contribute much to the likelihood of innovation" (1993: 146). Several authors argue that creatives would be hampered by too much structure and organizational rules. Creative people would be constricted in their work and demotivated when forced into dull routines or tightly structured working processes. While "factory-style production is widely felt to be inimical to the kinds of creativity necessary to make profits" (Hesmondhalgh 2007: 68), working conditions with lose control of the creative input, the "freedom to explore [...] ideas" (Killebrew 2005: 104) and freedom in decisions and actions as well as autonomy of the people working there support intrinsic motivation which in turn enhances creativity (Küng 2008: 2f.). Creative workers would consider self-control and selfactualization as highly important (Raudsepp 1963: 128). They need autonomy (Scott 1995: 68), a risk space (Bilton / Leary 2002: 59) for their at times subversive (Florida 2002: 31) work.

At the same time this means that creative workers are not only and not predominantly motivated by money. "Intrinsic motivation is conducive to creativity, but extrinsic motivation is detrimental" (Amabile 1996: 15). Thus standard goodies such as bonuses or a bigger company car might not work. That said, some form of extrinsic motivation is influential such as reputation and peer praise. The effect of extrinsic motivation is determined by individual and contextual factors. It depends on the individ- 
ual's perception of environmental factors and personal experience. The same individuality applies to the intrinsically motivated state, while the positive effect of intrinsic motivation on creativity still remains unchallenged in social psychology (Hennessey 2003: 183-198). The downside for creatives is that their intrinsic motivation is easily exploited by commissioners who employ them in precarious contracts. There is one other kind of extrinsic motivation that can be successful as it addresses the creative's ego: "Enable the artist to do something interesting or exiting enhances the quality of work" (Torr 2008: 62). However it is hard to tell what is regarded interesting or exciting by the creative worker so - following this idea - maybe it would be the best solution to forget about the profit motive in the beginning: "Creative people produce their best work when they do it for its own sake" (Torr 2008: 62).

Even if most extrinsic motivations fail some kind of external influence has to be provided: Several authors emphasize the importance of deadlines. Many creative workers would be longing for perfection and would get lost in ever more revisions of their work if there is no external pressure (Scott 1995: 69). The creative process has to adhere to economic concerns of the management. It has to be structured and fit into an organizational setting that makes sure that constraints of time and money are met (Ettema 1982). Indeed empirical findings reveal that certain constraints in financial and time resources foster the creative process leading to innovative output while boundless freedom in budget and time have negative effects on the process (Fröhlich 2008: 160f.). It might be opposed that Fröhlich focuses on the result, on the innovative product, but her argumentation draws on findings that refer to the worker's motivation - therefore it can be deduced that those effects can also be detected in the creative process itself.

Conceptualized as a group effort creativity in organizations depends on the team composition. The group of people working together in a project is not a simple aggregation of individuals but a social context determining creative behavior which - as empirical research has revealed (Fröhlich 2008: 153) - is supported by a "diversity of perspectives and backgrounds" (Küng 2008: 3) of the people working together.

If the work is finally completed the managers, i.e. motivators, are not done: Creative workers are at times regarded as feedback-junkies. They care about their product (Caves 2000) and thus would constantly want to talk about the successful and "almost successful" aspects of their work in order to remain motivated. 
Finally flat organizations would be conducive for the creative process (Scott 1995: 69; Andriopoulos 2001: 837). A democratic-collaborative style of leadership, boundless interactions with the employees, encouragement, respect and an open dialogue have a positive effect on creativity in organizations (Killebrew 2005: 103f.; Fröhlich 2008: 166; Küng 2008: 3). Creatives love to explain their impressive idea to the decision makers not the "bean counters" in middle management.

This set of suggestions is cursory only, but it provides an idea of the type of suggestions you find in the literature. We could extend this list almost infinitely with ever more suggestions. All of them intuitively comprehensible but hardly one of them truly measurable. The gist seems to be that you need to pamper creative stuff, provide them with resources and freedom you would never allow ordinary uncreative workers. What is worse, all you achieve is an increased chance of creative output, no guarantee. And then there is another issue: If it is true that creative workers need a certain degree of freedom and need to be allowed to work independently of the usual pressures and constrictions the question is "how much?".

Referring to media management different types of media call for different balances between creative freedom and managerial control. Aris and Bughin (2009: 351f.) relate this to the two dimensions risk and hit ratio (the revenue share of top products). Hit driven media segments would call for significant freedom for creators due to high opportunity costs for missing out a hit. For high risk media segments such as movie production or free TV they suggest freedom should be granted only in the initial phase followed by a rigid selection of project and a tight control of the actual production process.

It is reasonable to believe that there is a ceiling effect where additional freedom or risk space has no marginal effect on creativity as such and, more importantly from a managerial standpoint, on useable creativity. In the end managing creative workers seems to be just as fuzzy as the creative process itself.

\section{Peculiarities of creativity in the media business}

Research on creativity suggests, that it may be relevant in almost any industry. Still it is argued that creativity - and especially cultural creativity is more important in the so called creative or cultural industries in general and in the media industry in particular. These rely on "individual crea- 
tivity" and the fact, that (this) creativity constitutes "the most crucial element in the generation of new products, competitive advantage and increased productivity" (Banks et al. 2002: 256f.).

But what does this mean for the media in particular? In some respect the media industry is different from other industries since it is not necessary to encourage creativity within the workforce (e.g. Scott 1995), but - quite contrary - to tame it. Organizations do not have to push hard to wring some drops of creativity from controllers in suits or engineers in plaid shirts. Talent, actual or supposed is abundant. By definition of the creative and cultural industries creativity is a crucial element of media and regarded at as the expertise of the industry and part of the "professional ethos" of entertainment production (von Rimscha / Siegert 2011: 1022). Therefore the ability to creatively develop ideas is a key skill in the industry (e.g. Entertainment Master Class 2011); a creative workforce is being regarded as a crucial resource (Fröhlich 2010: 29) that can constitute a competitive advantage (Miller / Shamsie 1996: 526f.). Media production is a people's business depending on their skills and talents. Media companies must adapt to the creative employee not in the sense of giving in, but as a rational business decision since media companies rely on creativity as the very core of their product (Scott 1995: 68).

The creative workers have been focused on in research investigating the media workers' self-concept, biography and demography. Hesmondhalgh and Baker (2011) surveyed creative workers - explicitly labeling them as such - in the TV, music recording, and magazine publishing industry and evaluated their working profile and working conditions by describing elements of good and bad work of creative occupations. They describe the ambivalence of self-realization and self-exploitation as characteristic to the creative worker's occupations and identify creative autonomy as a crucial element of creative work. Other researchers, too, describe a duality inherent to the work in media production due to a discrepancy between the worker's personal view and the quality of the product they produce (Cantor 1971: xxxi; Turow 1992: 202). Media products seem to be a product of the interrelation and (potential) conflict between creativity and market orientation. This assumption is intelligible when creativity is aiming for more than problem solving. Interviewing producers and commissioners of light entertainment in Germany and Britain Fröhlich detected that idea selection was determined both by subjective evaluations (e.g. guided by intuition; also see von Rimscha 2012) as well as economic aspects, e.g. the demand or the possibility of economies of scale (Fröhlich 2010: 317-319). Still creativity on the one and commerce 
on the other hand are not contradictory extremes, but intimately connected and even dependent on each other (see e.g. Fröhlich 2010: 160f.; Roberts 2010).

Although the works cited in this article all apply specific definitions of creativity, it should be noted that these definitions are not necessarily consistent with the creative workers' own ideas of the term. Descriptions of creativity by creative workers might refer to different (elements of) activities, persons and roles (see e.g. Grindstaff 2002; Fröhlich 2010: 301; Becker et al. 2011; Karow 2011: 161). Apparently people working in different segments of the so called creative industries have a context sensitive working definition of creativity. Banks et al. find that "the meanings attached to creativity are variable and contested, and how, within firms, the definition and management of creativity may be highly context specific, being strongly determined by the internal workplace culture, and the external social and economic conditions within which firms operate" (Banks et al. 2002: 255).

However, despite the debates on the creative and cultural industries started by the New Labor government in "Cool Britannia" it is still not clear, whether the process of media production in general can be called a creative process or at least to what extent and which parts can be qualified as such.

Media production used to be a firmly creative business. In textbooks we still read that each media product would be a totally unique new product that cannot be assessed neither by distributors nor the audience. However the film d'auteur has all but disappeared and made way for high concept movies (Wyatt 1994). Magazines are based on licenses of existing foreign magazines (Siegert / Amstutz 2004). TV shows are based on formats (Lantzsch 2008) and Journalists are trained to process their research for all vectors (Keel 2011). For the last decades the industry has been working hard to constantly reduce the necessary amount of creativity for its output. A creative process might fail. Mitigating the risk of failure by augmenting control reduces creative latitude (Karow 2011: 207). Certainly creativity is still needed but much different than we might think and less than we might think. Creativity still characterizes media production on the level of the individuals, their actions and interactions, but it apparently decreases with regard to the product and even some steps of the process. In a format based TV landscape you need a great new idea only every now and then; most of the time creativity is replaced by problem solving: "How do we adapt that successful British format?". 
The adaption and production of a format based television show is - as Karow exemplifies - unique on an instance, but not on a type level. It is "still considered a creative process, [but] it is not perceived as innovative television making" (2011: 215). Since the positional good "true talent" would become more expensive and harder to promote media companies would rather turn to media artifacts such as casting show contestants (Aris / Bughin 2009: 90). In doing so they shift the focus of creativity from content to marketing. The "content industry" is much more concerned about squeezing the most out of one valuable idea reusing it as often as possible rather than coming up with a new one. In the current situation the pendulum seems to swing towards routine, standardization, structure, and emphasis on resource constraints rather than creativity. Or, to use the wording of Becker et al. (2011) the intensity in the "creativity-intensive process" media production is declining.

\section{$5 \quad$ Value creation through (cultural) creativity?}

The (economic) value of creativity in the media industry might be lower than suggested in heartwarming mission statements of media companies. The value of media for society is to inform, entertain and educate. Applying news values does not require much creativity and as long as entertainment and education does not need to be thought provoking they do not require much creativity either. If we trust some editors creativity can be replaced by rules of thumb such as "pets, babies and breasts".

But what about the value of creativity for the media firm? How much cultural creativity is good for your bottom line? Probably not much. Lobigs et al. (2005) believe creative TV formats could incorporate a first mover advantage for the innovator; however, until today this assumption lacks a strong empirical proof. It is fair to believe the contrary: Being an early imitator saves a lot on sunk development cost (i.e. creativity without a useful product) while you can build on the market created by the innovator (Gottlieb 2011: 266). That said, of course there still has to be a creative innovator to imitate.

Thus, it seems an emphasis on creativity is to entertainment media what an emphasis on quality is for newspapers (Siegert et al. 2011). Chances are you ask too much from a casual or somewhat interested audience and for sure it is not a mass market strategy bound for profit maximization. As for higher quality newspapers creativity usually comes at a cost. You need to allow for a certain amount of slack in your organization and for creative thinking that evidently goes nowhere. Higher investments in 
creativity (or quality) might not always be valued by your users; there is a diminishing marginal return on investment. Thus, mass market outlets such as RTL opt for the lowest common creative denominator (i.e. stereotypes and cliché) rather than original creative content.

However just as there is a market for newspaper with a quality based brand proposition there is a market for creativity based entertainment media. Those markets are usually smaller but audiences have a higher willingness to pay. Thus, it comes to no surprise that apart from public service media pay TV channels such as HBO offer more creative series than advertising funded free to air channels.

However the power relations in the industry bring about, that media firms on the distribution and packaging level of the industry do not have to worry too much about the cost of creativity while still harnessing its value. Creativity can at times be outsourced. In their study on new media SME Banks et al. found that "Creative inputs were often sourced through close knit and informal networks, often (though not necessarily) geographically 'clustered' around the firm, bound together by history of collaboration, shared experience and know how" (Banks et al. 2002: 259). Authors, scriptwriters and directors by far outnumber producers who in turn outnumber commissioners who in turn outnumber distributors. The risk and cost of creativity thus often remains with the weakest link (von Rimscha 2008) all the more since those creative have an intrinsic motivation (Amabile 1998) - they care about their product (Caves 2000). The proponents of the McKinsey funnel might be suggesting "more investment in product development" (Aris / Bughin 2009: 95f.); however what we see in the market is a retreat from production funding. Commissioners are no longer willing to use cost-plus deals but transfer the development risks in exchange for the foreign right to the production. Those companies who create their own in-house "production" departments such as ProSiebenSat.1 Media AG with the SevenPictures Film GmbH concentrate more on co-financing save bets than actually investing in cultural creativity.

To sum up we can state that creativity creates value in the media industry; however media managers have shifted the focus from less controllable cultural creativity towards technical creativity including business process optimization. The permanent effort of profit maximization in a commercialized media system is addressed by cost cutting and risk minimizing problem solving rather than by risky bets on the long term value of cultural creativity. The value of cultural creativity seems to be a public 
value and thus could be regarded as another element in the raison d'être of public service media.

\section{References}

Althuller, Genrich S. (1984): Creativity as an exact science: The theory of the solution of inventive problems. Gordon \& Breach: New York.

Altmeppen, Klaus-Dieter / Lantssch, Katja / Will, Andreas (2007): Flowing networks in the entertainment business: Organizing international TV format trade. In: International Journal on Media Management 9 (3), pp. 94-104.

Amabile, Teresa M. (1983): The social psychology of creativity: A componential conceptualization. In: Journal of Personality and Social Psychology 45 (2), pp. 357-376.

Amabile, Teresa M. (1996): Creativity in context. Westview Press: Boulder, CO.

Amabile, Teresa M. (1997): Motivating creativity in organizations: On doing what you love and loving what you do. In: California Management Review 40 (1), pp. 39-59.

Amabile, Teresa M. (1998): How to kill creativity: Keep doing what you're doing. Or, if you want to spark innovation, rethink how you motivate, reward, and assign work to people. In: Harvard Business Review (September-October), pp. 77-87.

Andriopoulos, Constantine (2001): Determinants of organisational creativity: A literature review. In: Management Decision 39 (10), pp. 834-841.

Aris, Annet / Bughin, Jacques (2009): Managing media companies: Harnessing creative value, 2nd edn. John Wiley \& Sons: Chichester.

Baker, Masxine (2006): Documentary in the digital age. Focal Press: Amsterdam, Boston, MA.

Banks, Mark / Calvey, David / Owen, Julia / Russell, David (2002): Where the art is: Defining and managing creativity in new media SMEs. In: Creativity and Innovation Management 11 (4), pp. 255-264.

Becker,Jörg / Seidel, Stefan / Müller-Wienbergen, Felix / Winkelmann, Axel (2008): Managing Creative Risks. Proceedings of the Fourteenth Americas Conference on Information Systems, Toronto, Canada August $14^{\text {th }}-17^{\text {th }}$.

Becker, Jörg / Bergener, Katrin / Schwehm, Marc O. / Voigt, Matthias (2011): Confirming BPM theory in creative industry context: A case study in the German TV industry. Proceedings of the European Conference on Information Systems.

Bilton, Chris (2007): Management and creativity: From creative industries to creative management. Blackwell Publishing: Malden, MA.

Bilton, Chris / Leary, Ruth (2002): What can managers do for creativity?: Brokering creativity in the creative industries. In: International Journal of Cultural Policy 8 (1), pp. 4964.

Buzan, Tony (1977): How to make the most of your mind. Colt Books: London.

Cantor, Muriel G. (1971): The Hollywood TV producer: His work and his audience. Basic Books: New York.

Caves, Richard E. (2000): Creative industries: Contracts between art and commerce. Harvard University Press: Cambridge, MA.

Creative Industries Task Force (CITF) (2001): The creative industries mapping document 2001, London.

Csikeszentmihalyi, Mibály (1996) Creativity: Flow and the psychology of discovery and invention. Harper Collins Publishers: New York.

Csikszentmihalyi, Mihály (1999): Creativity across the life-span: A systems view. In: Colangelo, Nicolas / Assouline, Susan G. (eds.): Talent development 3. Gifted Psychology Press, Scottsdale, AZ, pp. 9-18. 
de Bono, Edward (1981): Lateral thinking: Creativity step by step. Penguin Books: Harmondsworth.

Ekvall, Göran (1997): Organizational conditions and levels of creativity. In: Creativity and Innovation Management 6 (4), pp. 195-205.

Entertainment Master Class (2011): The programme. Online: http://www.entertainmentmasterclass.tv/the-programme_de.html [26.04.2012].

Ettema, James S. (ed.) (1982): Individuals in mass media organizations: Creativity and constraint. Sage Publications: Beverly Hills, CA.

Florida, Richard (2002): The rise of the creative class: And how it's transforming work, leisure, community and everyday life. Basic Books: New York.

Fröblich, Kerstin (2008): Organisation für Innovation: Kreativitätsfördernde Organisation in der TV-Unterhaltungsproduktion. In: Siegert, Gabriele / von Rimscha, M. Bjorn (eds.): Zur Ökonomie der Unterhaltungsproduktion. Herbert von Halem Verlag: Köln, pp. 151-173.

Fröblich, Kerstin (2010): Innovationssysteme der TV-Unterhaltungsproduktion: Komparative Analyse der sektoralen Innovationsbedingungen Deutschlands und Großbritanniens. VS Verlag: Wiesbaden.

Gordon, William J. J. (1961): Synectics: The development of creative capacity. Harper \& Row: New York.

Gottlieb, Neta-li E. (2011): Free to air? Legal protection for TV program formats. IDEAThe Intellectual Property Law Review 51 (2), pp 211-270.

Greenberg, Ellen (1992): Creativity, autonomy, and evaluation of creative work: Artistic workers in organizations. In: The Journal of Creative Behavior 26 (2), pp. 75-80.

Grindstaff, Laura (2002): The money shot: Trash, class, and the making of TV talk shows. University of Chicago Press: Chicago.

Hennessey, Beth A. (2003): Is the social psychology of creativity really social?: Moving beyond a focus on the individual. In: Paulus, Paul B. / Nijstad, Bernard A. (eds.): Group creativity. Oxford University Press: New York, Oxford, pp. 181-201.

Henry, Jane (1991): Making sense of creativity. In: Henry, Jane (ed.): Creative management. Sage Publications: London, pp. 3-11.

Hesmondhalgh, David (2007): The cultural industries. Sage Publications: London.

Hesmondhalgh, David / Baker, Susan (2011): Creative labour: Media work in three cultural industries. Routledge: London.

Hooker, Charles / Nakamura, Jeanne / Csikszentmibalyi, Mibály (2003): The group as mentor: Social capital and the systems model of creativity. In: Paulus, Paul B. / Nijstad, B. A. (eds.): Group creativity. Oxford University Press: New York, Oxford, pp. 225-244.

Howkins, J. (2002): The creative economy: How people make money from ideas. Penguin Books: London.

Jeffcutt, Paul / Pratt, Andy C. (2002): Managing creativity in the cultural industries. In: Creativity and Innovation Management 11 (4), pp. 225-233.

Karow, Milan (2011): Business process documentation in creative work systems: A design science study in television production. Doctoral Thesis, University of Münster.

KEA European Affairs (2009): The impact of culture on creativity. Brussels.

KEA European Affairs, Media Group (Turku School of Economics) / MKW Wirtschaftsforschung (2006): The economy of culture in Europe. Brussels.

Keel, Guido (2011): Journalisten in der Schweiz: Eine Berufsfeldstudie im Zeitverlauf. UVK: Konstanz.

Kepner, Charles H. / Tregoe, Benjamin B. (1965): The rational manager: A systematic approach to problem solving and decision making. McGraw-Hill: New York. 
Kerrigan, Susan (2010): Creative practice research: Interrogating creativity theories through documentary practice. Text (8), pp. 1-16.

Kerrigan, Susan / McIntyre, Philip (2010): The 'creative treatment of actuality': Rationalizing and reconceptualizing the notion of creativity for documentary practice. Journal of Media Practice 11 (2), pp. 111-130.

Killebrew, Kenneth C. (2005): Managing media convergence: Pathways to journalistic cooperation. Blackwell Publishing: Ames, IA.

Klausen, Soren. H. (2010): The notion of creativity revisited: A philosophical perspective on creativity research. Creativity Research Journal 22 (4), pp. 347-360.

Küng, Lucy (2008): Strategic management in the media: From theory and practice. Sage Publications: Los Angeles.

Lantzsch, Katja (2008): Der internationale Fernsehformathandel: Akteure, Strategien, Strukturen, Organisationsformen. VS Verlag: Wiesbaden.

Lobigs, Frank / Spacek, Dirk / Siegert, Gabriele / Weber, Rolf H. (2005): Mehr Rechtsschutz für TV-Formate? Eine medienökonomische und medienrechtliche Untersuchung. In: Medien / Kommunikationswissenschaft 53 (1), pp. 93-119.

Lubart, Todd I. / Mouchiroud, Christophe (2003): Creativity: A source of difficulty in problem solving. In: Davidson, Janet E. / Sternberg, Robert J. (eds.): The psychology of problem solving. Cambridge University Press: Cambridge, pp. 127-148.

Mierzejewskea, Bozena I. / Hollifield, C. Ann (2006): Theoretical approaches in media management research. In: Albarran, Alan B. / Chan-Olmsted, Sylvia M. / Wirth, Michael O. (eds.): Handbook of media management and economics. Lawrence Erlbaum Associates: Mahwah, NJ, pp. 37-66.

Miller, Daniel / Shamsie, Jamal (1996): The resource-based view of the firm in two environments: The Hollywood film studios from 1936 to 1965. In: The Academy of Management Journal 39 (3), 519-543.

Mintzberg, Henry (1976): Planning on the left side and managing on the right. In: Harvard Business Review 54 (4), pp. 49-58.

Osborn, Alex F. (1963): Applied imagination: Principles and procedures of creative problem-solving. Scribner: New York.

Paulus, Paul B. / Nijstad, Bernard A. (eds.) (2003): Group creativity. Oxford University Press: New York, Oxford.

Raudsepp, Eugene (1963): Managing creative scientists and engineers. Macmillan: New York.

Redmond, Matthew R. / Mumford, Michael D. / Teach, Richard (1993): Putting creativity to work: Effects of leader behavior on subordinate creativity. In: Organizational Behavior and Human Decision Processes 55 (1), pp. 120-151.

Roberts, James P. (2010): Revisiting the creative/commercial clash: An analysis of decisionmaking during product development in the television industry. In: Media, Culture \& Society 32 (5), pp. 761-780.

Sanyer, R. Keith (2006): Explaining creativity: The science of human innovation. Oxford University Press: Oxford.

Schlesinger, Philip (2007): Creativity: From discourse to doctrine? In: Screen 48 (3), pp. 377-387.

Scott, Randall K. (1995): Creative employees: A challenge to managers. In: The Journal of Creative Behavior 29 (1), pp. 64-71.

Seidel, Stefan (2009): A theory of managing creativity-intensive processes. Dissertation Thesis, Münster.

Seidel, Stefan / Müller-Wienbergen, Felix / Karow, Milan / Rosemann, Michael (2009): Toward the concept of pockets of creativity in business processes. Verona. 
Siegert, Gabriele / Amstutr, Priska (2004): Krisen-Management by Chance?: Der Fall Lizenz- und Joint-Venture Publikumszeitschriften. In: Friedrichsen, Mike / Schenk, Michael (eds.): Globale Krise der Medienwirtschaft?: Dimensionen, Ursachen und Folgen. Nomos: Baden-Baden, pp. 275-286.

Siegert, Gabriele / Gerth, Matthias A. / Rademacher, Patrick (2011): Brand identity-driven decision making by journalists and media managers: The MBAC model as a theoretical framework. In: International Journal on Media Management 13 (1), pp. 53-70.

Söndermann, Michael / Backes, Christoph / Arndt, Olaf / Brünink, Daniel (2009): Kultur- und Kreativwirtschaft: Ermittlung der gemeinsamen charakteristischen Definitionselemente der heterogenen Teilbereiche der „Kulturwirtschaft“ zur Bestimmung ihrer Perspektiven aus volkswirtschaftlicher Sicht, Köln, Bremen, Berlin.

Sternberg, Robert J. / Lubart, Todd I. (1999): The concept of creativity: Prospects and paradigms. In: Sternberg, Robert J. (ed.): Handbook of creativity. Cambridge University Press: Cambridge, pp. 3-15.

Torr, Gordon. (2008): Managing creative people: Lessons in leadership for the ideas economy. John Wiley \& Sons: Chichester.

Turow, Joseph (1992): Media systems in society: Understanding industries, strategies, and power. Longman: New York.

von Rimscha, M. Bjorn (2008): Risikomanagement in der Produktion und Entwicklung audiovisueller fiktionaler Unterhaltung. In: Siegert, Gabriele / von Rimscha, M. Bjorn (eds.) Zur Ökonomie der Unterhaltungsproduktion. Herbert von Halem Verlag: Köln, pp. 178-203.

von Rimscha, M. Bjorn (2012): „Man fühlt einfach, ob es gemacht werden muss“: Intuition bei der Risikosteuerung in der Spielfilmentwicklung. In: Müller-Lietzkoow, Jörg (ed.): Ökonomie, Qualität und Management von Unterhaltungsmedien: Theorie und Entwicklungen in Unterhaltungsmärkten. Nomos: Baden-Baden, pp. 129-149.

von Rimscha, M. Bjorn / Siegert, Gabriele (2011): Orientations of entertainment media workers. In: Media, Culture \& Society 33 (7), pp. 1009-1026.

Wallas, Graham. (1926): The art of thought. Harcourt, Brace and Company: New York.

Woodman, Richard W. / Sanyer, John E. / Griffin, Ricky W. (1993): Toward a theory of organizational creativity. In: The Academy of Management Review 18 (2), 293-321.

Wyatt, Justin (1994): High concept: Movies and marketing in Hollywood. University of Texas Press: Austin, TX. 